\title{
Perioperative changes of the intraocular pressure during the treatment of epiretinal membrane by using 25 - or 27-gauge sutureless vitrectomy without gas tamponade
}

\author{
This article was published in the following Dove Press journal: \\ Clinical Ophthalmology \\ 19 April 2017 \\ Number of times this article has been viewed
}

\author{
Hirotsugu Takashina ${ }^{1,2}$ \\ Akira Watanabe ${ }^{2}$ \\ Hiroshi Tsuneoka ${ }^{2}$ \\ 'Department of Ophthalmology, \\ National Hospital Organization \\ Sagamihara Hospital, ${ }^{2}$ Department \\ of Ophthalmology, Jikei University \\ School of Medicine, Tokyo, Japan
}

\begin{abstract}
Purpose: The purpose of this study was to compare perioperative intraocular pressures (IOPs) in 25- or 27-gauge microincision vitrectomy surgery (MIVS) and to evaluate the stability of postoperative sclerotomy closure.

Materials and methods: This is a retrospective review of 147 eyes treated for epiretinal membrane by using 25- or 27-gauge MIVS as the initial vitrectomy (25-gauge phacovitrectomy [25-P group]: 73 eyes, 25-gauge vitrectomy alone [25-A group]: 15 eyes, 27-gauge phacovitrectomy [27-P group]: 47 eyes, and 27-gauge vitrectomy alone [27-A group]: 12 eyes). Statistical analyses of perioperative IOPs on preoperative day (PreOp), postoperative day (POD)1, POD2, postoperative week 1 , and postoperative month 1 were performed.

Results: All self-sealing sclerotomies were obtained without gas tamponade at the end of surgery. Also, no significant differences were noted in the age and axial length among the 4 groups and in the surgical time between 25-P and 27-P groups and between 25-A and 27-A groups. Significant decreases in IOP were found at POD1 and POD2 in the 25-P, 25-A, and 27-P groups compared with PreOP, but not in the 27-A group.

Conclusion: Even though surgeons confirm that there is no leakage from sutureless sclerotomy and that a normal IOP is preserved at the end of 25- or 27-gauge MIVS, there is a possibility of postoperative sclerotomy leakage on the day of the surgery. Furthermore, postoperative sclerotomy self-sealing of the MIVS in previous intraocular lens implantation cases is considered to be acquired easily than that in phacovitrectomy.
\end{abstract}

Keywords: self-sealing, sclerotomy, leakage, remnant vitreous, ciliochoroidal detachment, microincision, phacovitrectomy

\section{Introduction}

Microincision vitrectomy surgery (MIVS) is premised on a sutureless sclerotomy (self-sealing sclerotomy) that is performed at the end of the surgery. ${ }^{1}$ One of the characteristic complications of MIVS is that the postoperative sclerotomy leakage due to fragile sclerotomy closure can lead to postoperative hypotony. Later, oblique incision and gas tamponade are reported to resolve the fragile sclerotomy closure, ${ }^{2-7}$ and nowadays, these procedures are very common. Furthermore, because the smaller size of the wound improves closure of the sclerotomy and helps to prevent hypotony, ${ }^{3,8-10}$ 27-gauge system, which Oshima et al reported in 2010, ${ }^{11}$ is considered to reduce the concern of fragile sclerotomy closure and postoperative hypotony. However, histological sclerotomy closure is impossible at the end of surgery, nevertheless the surgeons have
Correspondence: Hirotsugu Takashina Department of Ophthalmology, Jikei University School of Medicine, 3-19-I 8 Nishi-shinbashi Minato-ku, Tokyo 105-847I, Japan

Tel +8I 33433 I I I I ext 358 I

Fax +81334331936

Email two-shina@s7.dion.ne.jp $\mathrm{BY}$
hC for commercial use of this work, please see paragraphs 4.2 and 5 of our Terms (https://www.dovepress.com/terms.php). 
been released from the concern gradually. On the contrary, the possible mechanism of the elevation of intraocular pressure (IOP) that occurs after pars plana vitrectomy includes intraocular gas expansion, inflammation, hemorrhagic complication, silicone oil complication, papillary block, steroid response, and ciliary body edema. ${ }^{12}$ However, Lakhanpal et al reported that the inflammation associated with MIVS was less than with conventional 20-gauge vitrectomy, ${ }^{13}$ and the factors influencing less inflammation on MIVS may be sutureless sclerotomies, ${ }^{14,15}$ fluid stability due to higher cutting rate, ${ }^{16}$ and less scleral indentation by using wide-angle viewing system. Therefore, the surgeons should not pay attention to IOP elevation at the immediate postoperative period of MIVS. The "current MIVS," which over 10 years have passed from the initial report by Fujii et al, ${ }^{1}$ is considered to obtain less change of IOP at the immediate postoperative period. This study statistically analyzed the perioperative IOP in patients who underwent 25- or 27-gauge sutureless vitrectomy without gas tamponade for the treatment of epiretinal membrane and then evaluated the stability of the postoperative sclerotomy closure.

\section{Materials and methods}

This study was approved by the Institutional Ethics Committee of the National Hospital Organization of Sagamihara Hospital. After explaining the potential benefits along with the possible risks of the technique, written informed consent was obtained in accordance with the Declaration of Helsinki. A total of 147 eyes of 140 patients with idiopathic epiretinal membrane who underwent 25- or 27-gauge MIVS with oblique incisions as the initial vitrectomy at the National Hospital Organization of Sagamihara Hospital were retrospectively enrolled. Each surgery was performed by the same surgeon (Takashina). Between May 2013 and November 2014, 25-gauge MIVS was performed in 88 eyes of 82 consecutive patients (phacovitrectomy [25-P group]: 73 eyes of 67 patients and vitrectomy alone [25-A group]: 15 eyes of 15 patients), while between January 2015 and June 2016, 27-gauge MIVS was performed in 59 eyes of 58 consecutive patients (phacovitrectomy [27-P group]: 47 eyes of 46 patients and vitrectomy alone [27-A group]: 12 eyes of 12 patients). Exclusion criteria were past history of intraocular surgery except for cataract surgery, proliferative diabetic retinopathy, glaucoma, previous buckling, and intraoperative gas tamponade because of retinal detachment or vitreous hemorrhage. The first 5 cases that underwent the 27-gauge MIVS (performed in December 2014) were also excluded in order to avoid any potential bias due to the learning curve. MIVS was performed by using either the Alcon 25-gauge system or the Alcon 27 -gauge system $\left(25+{ }^{\circledR}\right.$ or $27+{ }^{\circledR}$ TOTAL PLUS ${ }^{\circledR} /$ Constellation $^{\circledR}$; Alcon Laboratories, Fort Worth, TX, USA). Phacoemulsification and implantation of intraocular lens (IOL) were simultaneously performed in cases in which the observation of the fundus was difficult. Phacoemulsification was performed before vitrectomy, and IOL implantation was performed just before the removal of the trocar cannulas at the end of the surgery. Oblique incisions of MIVS that were vertical to the limbus at an angle of $45^{\circ}$ to the sclera were placed $3.5 \mathrm{~mm}$ posterior to the limbus. The sclerotomy for the intraocular infusion was made in the inferotemporal quadrant, and two sclerotomies for the intraocular manipulations were made in the superonasal and superotemporal quadrants. In each case, minimal peripheral vitrectomy was performed for the existence of remnant vitreous (no vitreous incarceration to the point of the intraocular trocar cannula) by using a wide-angle viewing system (Resight ${ }^{\mathbb{R}}$; Carl Zeiss, San Leandro, CA, USA). At the end of the surgery, each sclerotomy was compressed by using the tip of the forceps in order to promote sclerotomy self-sealing. The self-sealing status was confirmed by determining that there was no existence of increasing bleb formation and the presence of a normal IOP by tactile examination. Age, axial length, surgical time, perioperative IOP that were observed on the preoperative day (PreOp), postoperative day (POD)1, POD2, postoperative week (POW)1, and postoperative month (POM)1 were collected from the medical records. PreOp, POW1, and POM1 were measured by a non-contact tonometer (TONOREFII; Nidek, Aichi, Japan) and measured again by Goldmann applanation tonometer if the IOP was $<10 \mathrm{mmHg}$ or $>20 \mathrm{mmHg}$. POD1 and POD2 were measured by Goldmann applanation tonometer. Statistical analyses performed in this study included comparisons of the age, axial length, and PreOp among the 4 groups by using one-way factorial analysis of variance, comparisons of the surgical time between the 25-P and 27-P groups and between the 25-A and 27-A groups by using Student's $t$-test, and comparisons of the IOPs between each postoperative period (from POD1 to POM1) and PreOp in each group by using Student's $t$-test. All the statistical analyses were performed by using Excel software (Microsoft, Redmond, WA, USA). $P$-values $<0.05$ were considered statistically significant.

\section{Results}

Since all cases in the 25-A and 27-A groups were pseudophakia, lens sparing vitrectomy was not performed in these groups. At the end of surgery, a normal IOP was obtained 
Table I Mean values for each factor in all of the groups

\begin{tabular}{lllll}
\hline & $\mathbf{2 5 - P}$ & $\mathbf{2 5 - A}$ & $\mathbf{2 7 - P}$ & $\mathbf{2 7 - A}$ \\
\hline Age (years) & $71.3 \pm 7.6$ & $73.9 \pm 9.8$ & $72.9 \pm 6.3$ & $77.7 \pm 3.8$ \\
Axial length (mm) & $23.6 \pm 1.3$ & $23.6 \pm 1.6$ & $23.7 \pm 1.3$ & $22.9 \pm 1.1$ \\
Surgical time (minutes) & $38.0 \pm 6.6$ & $29.7 \pm 9.6$ & $37.0 \pm 7.6$ & $30.8 \pm 5.3$ \\
\hline
\end{tabular}

Note: Data are expressed as mean \pm standard deviation.

Abbreviations: 25-P, 25-gauge phacovitrectomy; 25-A, 25-vitrectomy alone; 27-P, 27-gauge phacovitrectomy; 27-A, 27-vitrectomy alone.

through the use of a balanced salt solution (BSS Plus ${ }^{\circledR}$; Alcon Laboratories) tamponade; therefore, none of the cases required air or gas tamponade to promote the sclerotomy self-sealing or needed sclerotomy suture placement. As no bleb formation was observed during the postoperative examinations, none of the sclerotomies required any supplemental suture placement postoperatively. No hemorrhagic complications (hyphema or vitreous hemorrhage) and no fibrin exudations were found during the postoperative examinations. Table 1 summarizes the mean values for the age, axial length, and surgical time. There were no significant differences in the age and axial length among the 4 groups and in the surgical times between the 25-P and 27-P groups and between the 25-A and 27-A groups, and there was a significant difference in PreOp among the 4 groups. Table 2 summarizes the mean values for the perioperative IOP in all groups and comparisons of the IOPs between the postoperative period (from POD1 to POM1) and PreOp in each group (Figure 1). Significant decreases in IOP were found at POD1 and POD2 in the 25-P, 25-A, and 27-P groups compared with PreOp, but not at any postoperative periods in the 27-A group.

Table 2 Mean value of the IOP during the perioperative period and comparisons of the postoperative IOPs with the PreOp in each group

\begin{tabular}{|c|c|c|c|c|c|}
\hline Group & PreOp & PODI & POD2 & POWI & POMI \\
\hline 25 -gauge & $14.8 \pm 2.7$ & $12.2 \pm 4.6$ & $11.9 \pm 3.5$ & $14.0 \pm 3.5$ & $13.9 \pm 3.1$ \\
\hline phacovitrectomy & $(8-22)$ & $(4-24)$ & $(5-22)$ & $(5-23)$ & $(8-20)$ \\
\hline$(n=73)$ & & $P=<0.00 \mathrm{I}$ & $P=<0.001$ & $P=0.139$ & $P=0.072$ \\
\hline 25 -gauge & $13.2 \pm 2.7$ & $9.9 \pm 3.6$ & $10.9 \pm 2.8$ & $13.9 \pm 3.5$ & $15.1 \pm 3.6$ \\
\hline vitrectomy alone & $(9-19)$ & $(5-20)$ & $(7-16)$ & $(6-22)$ & $(9-22)$ \\
\hline$(n=15)$ & & $P=0.011$ & $P=0.036$ & $P=0.537$ & $P=0.128$ \\
\hline 27 -gauge & $14.3 \pm 3.0$ & $12.7 \pm 4.0$ & $12.3 \pm 3.6$ & $13.9 \pm 3.1$ & $13.6 \pm 3.0$ \\
\hline phacovitrectomy & $(9-20)$ & $(5-25)$ & $(7-24)$ & $(|0-2|)$ & $(9-21)$ \\
\hline$(n=47)$ & & $P=0.032$ & $P=0.004$ & $P=0.566$ & $P=0.26 \mathrm{I}$ \\
\hline 27-gauge & $12.2 \pm 2.7$ & $11.9 \pm 2.6$ & $11.8 \pm 3.3$ & $13.3 \pm 2.9$ & $14.3 \pm 2.7$ \\
\hline vitrectomy alone & $(9-16)$ & $(7-15)$ & $(7-18)$ & $(10-19)$ & $(10-19)$ \\
\hline$(n=12)$ & & $P=0.818$ & $P=0.739$ & $P=0.316$ & $P=0.063$ \\
\hline
\end{tabular}

Notes: Data are expressed as mean $(\mathrm{mmHg}) \pm$ standard deviation (upper) and ranges (lower). $P$-values $<0.05$ were considered statistically significant.

Abbreviations: IOP, intraocular pressure; PreOp, preoperative day; POD, postoperative day; POW, postoperative week; POM, postoperative month.

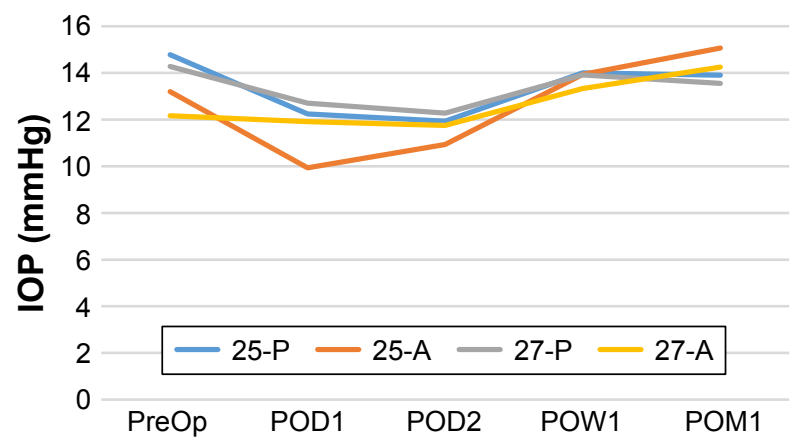

Figure I The mean IOP during the perioperative period in each group. Abbreviations: 25-P, 25-gauge phacovitrectomy; 25-A, 25-vitrectomy alone; 27-P, 27-gauge phacovitrectomy; 27-A, 27-vitrectomy alone; IOP, intraocular pressure; PreOp, preoperative day; POD, postoperative day; POW, postoperative week; POM, postoperative month.

\section{Discussion}

The significant decreases in IOP compared with the PreOp (POD1 and POD2) improved at POW1 in the three groups (25-P, 25-A, and 27-P) (Table 2). Postoperative transient hypotony, which is one of the characteristic complications of MIVS, resolved spontaneously by the 1-week postoperative follow-up examination, ${ }^{6,17,18}$ and this was caused by ciliochoroidal detachment due to immediate postoperative hypotony that results from the postoperative sclerotomy leakage on the day of surgery. ${ }^{19}$ Therefore, the existence of postoperative leakage on the day of surgery could not be denied in this study. Also, it was confirmed that there was no leakage from sutureless sclerotomy and that a normal IOP was preserved at the end of the surgery. However, since Kapran and Acar described that subclinical amount of leakage might make hypotony at 2 hours postoperatively in the case of normal IOP at the end of surgery and at POD $1,{ }^{20}$ Song et al described postoperative subclinical leakage from sclerotomy in the case of successful self-sealing on the operating table, ${ }^{21}$ and Rizzo et al described histopathological sclerotomy heals with a fiblin plug within 6-12 hours after surgery, ${ }^{22}$ it is very likely that postoperative sclerotomy leakage could easily occur within the first 6 hours in the case which was judged successful selfsealing at the end of surgery by the surgeon. Therefore, the possibility of sclerotomy leakage on the day of surgery was suggested in each gauge system of this study. On the contrary, the significant IOP decrease compared with the PreOp was not found in the 27-A group (Table 2). It is considered that less sclerotomy leakage in 27 -gauge system than in 25 -gauge system due to smaller gauge influenced the result. However, the other factors, such as cataract surgery, could influence the sclerotomy leakage, because of the different IOP changes between the 27-P and 27-A groups (Table 2). In 1989, 
Han et al described that combined cataract surgery using pars plana lensectomy was one of the risk factors of immediate postoperative IOP elevation due to lens particles or uveal pigment dispersion, ${ }^{12}$ nevertheless, the articles in recent years described that combined cataract surgery using phacoemulsification was not a risk factor of immediate postoperative IOP elevation. ${ }^{23,24}$ Therefore, combined cataract surgery is hard to be a risk of IOP decrease at immediate postoperative period in recent years. Remnant vitreous around sclerotomy, which promotes self-sealing, was considered to be different between the 27-A and 27-P groups. Peripheral vitreous shaving was performed under aphakia in the 27-P group and under pseudophakia in the 27-A group. Despite using a wide-angle viewing system, peripheral vitreous shaving was slightly harder to perform in previous IOL implantation cases due to the disturbance of anterior chamber depth or anterior capsule opacity. Therefore, as a greater volume of remnant vitreous can promote more certain self-sealing sclerotomy closure in previous IOL implantation cases, no significant decreases in IOP were found in the 27-A group. The gauge size may be more influential to sclerotomy self-sealing than remnant vitreous because of similar IOP change between the 25-A and 25-P groups.

There were some limitations for the current study. First, the sample sizes for the 25-A and 27-A groups were small. Second, the potential differences in the inflammation between the 25-and 27-gauge systems were not considered. This study was not designed to compare the MIVS with conventional 20-gauge vitrectomy, but rather simply compared the MIVS results. Furthermore, all sclerotomies were sutureless, and no significant differences in the surgical times between the 25-A and 27-A groups or the 25-P and 27-P groups were found (Table 1). Therefore, it is hardly considered to influence the resolution in this study. Third, IOP was not measured in the immediate postoperative period (eg, 1 and 3 hours) in this study. Therefore, the presence or absence of wound leakage could not be substantiated correctly.

In conclusion, even though surgeons confirm that there is no leakage from sutureless sclerotomy and that a normal IOP is preserved at the end of 25- or 27-gauge MIVS, postoperative sclerotomy leakage is possible on the day of the surgery. Furthermore, postoperative sclerotomy self-sealing of the MIVS in previous IOL implantation cases is considered to be easier to obtain than that in phacovitrectomy.

\section{Acknowledgments}

The authors are grateful to Dr Nobutaka Shiotani and Dr Nazuki Tamura for their support during the surgeries and their helpful discussions.

\section{Disclosure}

The authors report no conflicts of interest in this work.

\section{References}

1. Fujii GY, De Juan E Jr, Humayun MS, et al. Initial experience using the transconjunctival sutureless vitrectomy system for vitreoretinal surgery. Ophthalmology. 2002;109(10):1814-1820.

2. Lin AL, Ghate DA, Robertson ZM, O'Sullivan PS, May WL, Chen CJ. Factors affecting wound leakage in 23-gauge sutureless pars plana vitrectomy. Retina. 2011;31(6):1101-1108.

3. Singh RP, Bando H, Brasil OF, Williams DR, Kaiser PK. Evaluation of wound closure using different incision techniques with 23-gauge and 25-gauge microincision vitrectomy systems. Retina. 2008;28(2): 242-248.

4. Shimada H, Nakashizuka H, Mori R, Mizutani Y, Hattori T. 25-gauge scleral tunnel transconjunctival vitrectomy. Am J Ophthalmol. 2006; 142(5):871-873.

5. Hsu J, Chen E, Gupta OP, Fineman MS, Garg SJ, Regillo CD. Hypotony after 25-gauge vitrectomy using oblique versus direct cannula insertions in fluid-filled eyes. Retina. 2008;28(7):937-940.

6. Gupta OP, Weichel ED, Regillo CD, et al. Postoperative complications associated with 25-gauge pars plana vitrectomy. Ophthalmic Surg Lasers Imaging. 2007;38(4):270-275.

7. Shimada H, Nakashizuka H, Mori R, Mizutani Y. Expanded indications for 25-gauge transconjunctival vitrectomy. Jpn J Ophthalmol. 2005; 49(5):397-401.

8. Chen D, Lian Y, Cui L, Lu F, Ke Z, Song Z. Sutureless vitrectomy incision architecture in the immediate postoperative period evaluated in vivo using optical coherence tomography. Ophthalmology. 2010; 117(10):2003-2009.

9. Misra A, Yen GH, Burton RL. 23-gauge sutureless vitrectomy and 20-gauge vitrectomy: a case series comparison. Eye (Lond). 2009;23(5): $1187-1191$

10. Papaefthymiou I, Petropoulos LK, Mangioris G, Mendrinos E, Pournaras CJ. Safety of 20-gauge transconjunctival sutureless vitrectomy. Ophthalmologica. 2013;230(4):207-214.

11. Oshima Y, Wakabayashi T, Sato T, Ohji M, Tano Y. A 27-gauge instrument system for transconjunctival sutureless microincision vitrectomy surgery. Ophthalmology. 2010;117(1):93-102.

12. Han DP, Lewis H, Lambrou FH Jr, Mieler WF, Hartz A. Mechanisms of intraocular pressure elevation after pars plana vitrectomy. Ophthalmology. 1989;96(9):1357-1362.

13. Lakhanpal RR, Humayun MS, de Juan E Jr, et al. Outcomes of 140 consecutive cases of 25 -gauge transconjunctival surgery for posterior segment disease. Ophthalmology. 2005;112(5):817-824.

14. Kim M, Park YS, Lee DH, Koh HJ, Lee SC, Kim SS. Comparison of surgical outcome of 23-gauge and 25-gauge microincision vitrectomy surgery for management of idiopathic epiretinal membrane in pseudophakic eyes. Retina. 2015;35(10):2115-2120.

15. Pavlidis M, Korber N, Hohn F. Surgical and functional results of 27-gauge vitrectomy combined with coaxial $1.8 \mathrm{~mm}$ microincision cataract surgery a consecutive case series. Retina. 2016;36(11):2093-2100.

16. Rizzo S, Barca F, Caporossi T, Mariotti C. Twenty-seven gauge vitrectomy for various vitreoretinal diseases. Retina. 2015;35(6): $1273-1278$.

17. Byeon SH, Chu YK, Lee SC, Koh HJ, Kim SS, Kwon OW. Problems associated with the 25 -gauge transconjunctival sutureless vitrectomy system during and after surgery. Ophthalmologica. 2006;220(4): 259-265.

18. Gupta OP, Ho AC, Kaiser PK, et al. Short-term outcomes of 23-gauge pars plana vitrectomy. Am J Ophthalmol. 2008;146(2):193-197.

19. Yamane S, Inoue M, Arakawa A, Kadonosono K. Early postoperative hypotony and ciliochoroidal detachment after microincision vitrectomy surgery. Am J Ophthalmol. 2012;153(6):1099-1103.

20. Kapran Z, Acar N. Removal of silicone oil with 25-gauge transconjunctival sutureless vitrectomy system. Retina. 2007;27(8):1059-1064. 
21. Song Y, Shin YW, Lee BR. Adjunctive use of a novel releasable suture technique in transconjunctival vitrectomy. Retina. 2011;31(2): 243-249.

22. Rizzo S, Genovesi-Ebert F, Patelli F. Small gauge vitrectomy: anesthesia, incision technique and cannula removal. In: Rizzo S, Patteli F, Chow DR, editors. Vitreo-retinal Surgery [Essentials in Ophthalmology. Krieglstein GK, Weinreb RN, series editors]. 1st ed. Heidelberg, Germany: Springer-Verlag; 2009:53-54.
23. Hasegawa Y, Okamoto F, Sugiura Y, Okamoto Y, Hiraoka T, Oshika T. Intraocular pressure elevation in the early postoperative period after vitrectomy for rhegmatogenous retinal detachment. Jpn J Ophthalmol. 2012;56(1):46-51.

24. Wong R, Gupta B, Williamson TH, Laidlaw DA. Day 1 postoperative intraocular pressure spike in vitreoretinal surgery (VDOP1). Acta Ophthalmol. 2011;89(4):365-368.

\section{Publish your work in this journal}

Clinical Ophthalmology is an international, peer-reviewed journal covering all subspecialties within ophthalmology. Key topics include: Optometry; Visual science; Pharmacology and drug therapy in eye diseases; Basic Sciences; Primary and Secondary eye care; Patien Safety and Quality of Care Improvements. This journal is indexed on

Submit your manuscript here: http://www.dovepress.com/clinical-ophthalmology-journal

\section{Dovepress}

PubMed Central and CAS, and is the official journal of The Society of Clinical Ophthalmology (SCO). The manuscript management system is completely online and includes a very quick and fair peer-review system, which is all easy to use. Visit http://www.dovepress.com/ testimonials.php to read real quotes from published authors. 